\title{
Digital sovereignty and approaches to governing globalized data spaces
}

\begin{abstract}
The dimension of digital sovereignty is currently evolving as a key focus of transnational digital policy debates. The term 'sovereignty' relates back to the early days of International Relations as a territorial space of sovereign power. However, in today's transnational 'fluid' data spaces, the concept of sovereignty requires a conceptual revision. This article provides first an overview of current digital sovereignty debates, in the second part a critical review of the current 'toolbox' of digital policy approaches in an international spectrum. The third part suggests an entirely new approach to revise debates of sovereignty in new contexts of the 'data citizen' and a global public sphere of deliberation.
\end{abstract}

Over the past years, digital sovereignty has become a key term in international scholarship, in public policy and civil society debates. The original meaning of sovereignty as defined in the legendary Treaty of Westphalia in 1648 relates to the sovereign rights of a "polity" over "territory" and has laid the foundation of the international order of the modern sovereign state system of territorial rule. Sovereignty is practiced internally within a state where the legitimate government exercises "polity" over state territory but also externally by representing the state's sovereign interests in International Relations, Foreign Policy and in intergovernmental multi-stakeholder organisations. ${ }^{1}$ However, a debate of sovereignty in digital contexts emerged about two decades ago and began to challenge these original concepts of modern statehood, polity and sovereign territory.

Already in the early days of the Internet in the 1980s, not only the internationalization but the deterritorialization of national public sovereign civic space was seen as one of the characteristics of the new sphere of digitally hyperlinked communication. Internet users, mainly from Western democratic world regions, were astounded by the opportunity to deliberate with citizens elsewhere without geographical boundaries and soon envisioned the potential of a new potential for democratic deliberation through decentralization of communication. The transnational "stretching" and the disembedding of national "polity" over civic space inspired a sense of freedom of civic interaction with the potential of strengthening an international civil society. Cyberspace - as the Internet was

1 E.g. Ian Clark, Legitimacy in International Society, Oxford 2005; David Held, 'The Decline of the Nation State’, in: Geoff Eley and Suny Rigor (eds.), Becoming National, New York 1996, 407-417.

Ә Open Access. (C) 2021 Ingrid Volkmer, published by De Gruyter. (c) BY-NC-ND This work is licensed under the Creative Commons Attribution-NonCommercial-NoDerivatives 4.0 International License.

https://doi.org/10.1515/9783110679151-007 
called at the time - was seen as a liberal self-regulated sovereign sphere, detached from national boundedness - a borderless public space - for citizens. However, as soon became clear, this public space was mainly accessible for tech-savvy citizens across Western countries who engaged in this emerging international communicative dimension open to all kinds of political debate, side-by-side to the nationally bounded public territories and beyond the agenda of nationally oriented broadcast and print media. In the early 1990s, with advanced technological infrastructures and the broadening of connectivity, the commercialisation of this "liberal" democratic space was driven by private corporate interests, and a platformization through commercial standards. Sociologist Saskia Sassen was deeply concerned and warned that "powerful corporate actors" were "strengthening the role of private digital space" and - overall - were "altering the structure of public digital space". ${ }^{2}$ Building on Ruggie's problematization of modern territoriality, ${ }^{3}$ she foresaw that these processes would potentially go hand-in-hand with power dynamics of a new type, emerging transnational regimes and digital corporations who - over time have the "potential for producing fundamental changes to the systems of states". 0 ther critical debates at the time cautioned against too optimistic visions of international digital space due to neoliberal commercialization and the fact that the remaining civic sovereign side of cyberspace began to produce its own "borders". The term of "borders" did not relate back to the traditional understanding of sovereign - geographical - territory but to new digitally raised boundaries to demarcate the international digital "territory". The "digital divide" was seen as one of the boundaries excluding populations in developing regions due to the lack of technological access. Another boundary was seen in the dominance of the English language and the linguistic exclusion of large non-English speaking world regions. These debates cautioned against overly optimistic assessments of digital space and assumed that, overall, the vision of deliberation among citizens across countries and free speech were a myth and more nuanced approaches were required. ${ }^{5}$ Other critical voices, such as the US-American legal scholar Lawrence Lessig, shifted the focus towards the digital architecture towards programming - and the power dynamics of "code" determining the

2 Cf. Saskia Sassen, 'On the Internet and Sovereignty', in: Indiana Journal of Global Legal Studies 5 (1998), 545-559, 547.

3 John G. Ruggie, 'Territoriality and Beyond: Problematizing Modernity in International Relations', in: International Organization 47 (1993), 139-174.

4 Saskia Sassen, Losing Control? Sovereignty in an Age of Globalization, New York 1996, 26.

5 See Brian Kahin and Charles Nesson (eds.), Borders in Cyberspace: Information Policy and the Global Information Infrastructure, Cambridge/MA 1997. 
architecture of international cyber territories. Lessig suggested to understand "code" as law and digital architectures as diminishing the powers of national sovereign structures enabling a communicative space that is no longer shaped by national polity but by software logic. ${ }^{6}$

Whereas these first decades relate to an emerging transnational digital territory of civic but also - increasingly - corporate sovereign space, a few years later and in the already more advanced transnational digital sphere, cyberterrorism and cyberwar posed "real" challenges to territorial sovereign power and resulted in the tightening of national security responses by the U.S., Russia and the Middle East. ${ }^{7}$ While the Internet was widely seen as a corporate space by governments - and not a civic sphere! - digital national security threats were perceived as actual assault on sovereign territory, followed by national responses. In the aftermath of the Snowden revelations in 2013, we see a new awareness among citizens concerning states not so much as a legitimate "polity" attempting to regulate national digital space but rather as a "vague" state, implementing new polity tools such as surveillance practices to monitor civic interaction across countries in now transnational digital spheres. ${ }^{8}$ The Cambridge Analytica scandal in 2018 illuminated not only the massive data breaches of corporate digital platforms but also the power of microtargeting strategies to influence public opinion in election campaigns. Especially the influence on elections has alerted governments of democratic societies to the fact that sovereign communicative space has become "fluid" and "polity" of communicative space has dissolved into a rogue assemblage of power of transnational corporate interests.

Over the past years, debates about digital sovereignty seemed to accept the dominance of big tech corporate power providing the infrastructure of civic communication (from Facebook, Microsoft, Amazon to the Chinese social media platform TikTok) and the - to use a Habermasian term - "colonialization" of civic space by all kinds of data monopolies, their values and interests. While the debates outlined above related - even in broad terms - still somehow to the traditional concept of national sovereign spaces, recent debates divert into very specific types of power dynamics of technologies and digital communication. For example, some scholars address how globally operating big tech companies,

6 Cf. Lawrence Lessig, Code: And Other Laws in Cyberspace, New York 1999.

7 E.g. Ralf Bendrath et al, 'From Cyberterrorism to Cyberwar Back and Forth: How the United States Securitized Cyberspace', in: Johan Eriksson and Giampiero Giacomello (eds), International Relations and Security in the Digital Age, London 2007, 57-82; Hamoud Salhi, 'Assessing theories of information technology and security in the Middle East', in: ibid., 106-131.

8 E.g. Arne Hintz and Ian Brown, 'Enabling Digital Citizenship? The Reshaping of Surveillance Policy After Snowden', in: International Journal of Communication 11 (2017), 782-801. 
such as Facebook, claim global platform sovereignty and assume the de facto right to practice their own approach to governance of interaction of their three billion users worldwide, deeply undermining state sovereignty across continents regarding the protection of civic rights in public spaces. ${ }^{9}$ However, in addition to these quasi corporate formations of governance, debates also address new concepts of civic "territory" and a territorial "logic" arguing that the dimension of "platforms" is now the "new grammar for territories". ${ }^{10}$ The dimension of polity is also completely revised through a focus on data sovereignty, spectrum sovereignty and even computer sovereignty. ${ }^{11}$ Each nuanced terminology reflects the increasing diversity and - overall - plethora of power interests of new polity interfaces governing digital civic territory, ranging from platform power to algorithm design by the individual controller. However, debates address the ways how civil society groups also claim technological sovereignty when demanding noncorporate and encryption-based software for enacting citizenship across transnational digital spheres.

When taking these debates back into a conceptual context, it seems that this conceptual plethora of digital sovereign spaces does not address new "layers" of national sovereignty but rather overlay national sovereignty through a global governing logic through which national sovereignty of all types of societies is reconfigured, loosened up and is being made porous. ${ }^{12}$ Already in 2008, Manuel Castells captured these processes by arguing that all states are transitioning to "Network States" and are facing "contradictions between the historically constructed nature of institutions" and "the new functions and mechanisms they have to perform" while "still relating to their nation-bound societies". ${ }^{13}$ Today, more than a decade later, "network states" are the norm as citizens are densely connected, no longer only in the Western world but also in developing countries. Yet, the relations between traditional state structures, globalized big tech power and the accelerating digital dynamics constitute, as has recently been argued, “acute challenges for

9 E. g. Jose van Dijck, Thomas Poell and Martjn de Waal, The Platform Society. Public Values in a Connected World, New York 2018.

10 Stephane Grumbach, 'Digital Platforms: A New Grammar for Territories', in: Ethics in Progress 8 (2017), 101-116.

11 E.g. Stephane Couture and Sophie Toupin, 'What Does the Notion of 'Sovereignty' Mean when Referring to the Digital?', in: New Media \& Society 21 (2019), 2305-2322.

12 Cf. Benjamin Bratton, The Stack: on Software and Sovereignty. Cambridge/MA 2016.

13 Manuel Castells, 'The New Public Sphere: Global Civil Society, Communication Networks, and Global Governance', in: Annals of the American Academy of Political and Social Science 616/1 (2008), 78-93, 88. 
law- and policy-makers" when addressing “the interplay of 'code' and 'law', the cost of sovereignty, and the nonneutrality of technology". ${ }^{14}$

These acute challenges are at least somehow recognized today but they were not recognized two decades ago. All states, authoritarian as well as democratic ones, have turned a blind eye on digital developments at the time when today's global monopolies were beginning to establish themselves two decades ago - Google was launched in 1998 and Facebook in 2004. These platforms were not considered as "relevant" to national sovereign space and - in consequence - national regulation fully focused on national broadcasting and other national media outlets. Most governments practiced such a regulatory "side-byside" approach because digital spheres were not associated with national sovereign communicative territory. For example, while election campaign ads were heavily regulated on national broadcasting, no policy existed to address election campaign issues related to social media and search platforms. The Cambridge Analytica scandal illuminated the disruptive influence on voter behaviour and was a turning point for departing from the "side-by-side" approach as governments of democratic countries began to realize the influence of social media on societal political debate, on the dimension of political deliberation and, hence, the influence on legitimizing national polity.

We are now facing a new phase where all types of states are transitioning into "Network States". It seems that across society types, governments are just now beginning to reconfigure sovereignty, i.e. they start reclaiming digital space as national space. Authoritarian states (e.g. Russia, China, Saudi-Arabia, Brazil) have developed nationally specific strategies for nationalizing digital space. China is scaling up digital citizenship scoring, "dataveillance", ${ }^{15}$ the datafication of society, embracing cutting edge approaches of Artificial Intelligence to establish polity through a new type of data-driven authoritarianism. The Russian government is building an entirely Russian internet, completely disconnected from the global Internet routes with all Internet traffic domestically using a national domain name system. Developing countries, for example in the African region, also transition into "Network States" with a dedicated focus on building digital economy capacity. Various developing countries embrace the neoliberal corporatization of digital space and practice a new type of "side-by-side" approach: they invest in the national digital economy but, at the same time,

14 Paul Timmers, 'Challenged by "Digital Sovereignty"', in: Journal of Internet Law 23/6 (2019), 11-20, 11.

15 Claire Seunegeun Lee, 'Datafication, dataveillance, and the social credit system as China's new normal', in: Online Information Review 43/6 (2019), 952-970. 
practice "rogue" and ad hoc control of civic digital space. This control is exercised specifically in times of political crisis and protests through the complete shut-down of Internet servers and, hence, social media.

However, while these two types of transitioning processes operate with a clear vision to undermine civic spaces, the third type of societies, democratic countries, struggle. They struggle as digital civic space is not yet seen as a sovereign public territory in the same way as traditional linear media are. In European countries, where public territory is still today related to established traditions of national media, "public service" broadcasting is heavily regulated in the greatest detail to ensure the safeguarding of the public sphere while regulatory approaches to digital space are not related to new types of public interaction. The established system of regulatory procedures is well developed regarding national broadcasting. But when it comes to the regulation of digital spaces a paradigmatic shift towards a new perception of sovereign civic space has not yet been adopted. Ad hoc interventions are not enough as the dimension of national sovereignty in a globalized data world requires a new conceptual approach to respond to the challenge of the global governing logic by digital infrastructures. The aim should not be the regulation of ad hoc issues but rather a paradigmatic shift towards a holistic approach to digital sovereignty within globalized data spaces, not to overregulate but to safeguard the parameter of civic space within a globalized interdependent digital territory of deliberation. Such an approach is crucial for democratic countries in order to fully address the protection of civic space - which is the traditional sovereign model of polity of communicative territory - in today's fluid data spheres of Artificial Intelligence and the Internet of Things (IoT). As the OECD notes in a recent report, the "majority of national institutions, rules, regulatory frameworks are currently not designed to adequately deal with any of the emerging challenges related to digital technologies and civic space" as "countries and regions are starting to develop their own response to the global discourse, adopting disparate approaches toward oversight and regulation"16 which are often ad hoc policy interventions.

16 OECD Development Policy Papers 'Digital Transformation and the Future of Civic Space to 2030, Paris, No 29, Paris 2020, 36. 


\section{The "toolbox" of traditional national sovereignty regulation - and the reality of globalized data dynamics reaching into civic sovereign space}

On the one hand, civic deliberation is embedded in fluid transnational digital "ecosystems", while, on the other, a nationally bounded concept of sovereignty over communication spaces is still informing national digital policy approaches. Already in the early twentieth century, countries began to adopt national policies to address the nationally specific sovereign understanding of "public interest" in the regulation of the first mass medium - radio. For example, spectrum rights of national and international radio transmission were regulated in the U.S. as early as 1927 and, soon afterwards, the Federal Communication Commission was established in 1934 as a national entity to regulate the national broadcasting spectrum. ${ }^{17}$ As Hazlett notes, even in these early days "the legal thinking" came to "permit government control over the airwaves" and this included "the regulation of content, with officials selecting to license some communications over others." 18

This perception of national sovereign communicative space laid the foundation for nationally regulated television broadcasting also along "public service" models in European countries. This public service model included the safeguarding of the role of journalism as a "fourth estate", the balancing of advertising, and the elimination of "hate" speech from public spheres, especially in Germany. It also ensured the reflection of national cultural practice, the protection of minors, fair election campaign advertising and limited "foreign" ownership of media. ${ }^{19}$ This understanding of national sovereign communicative space established the regulatory paradigm, the narratives, the vocabulary, motives and frameworks for content regulation which is still in use today. These nationally specific themes of sovereign regulation of national broadcast media are extended to establish nationally specific policy motives to govern digital space. Singapore has a focus on Virtual Reality, AI and cybersecurity; Germany's digital policy priorities are connectivity, a Masterplan for AI and the regulation of "hate speech"; Australia has a focus on government, health and medicine. Kenya's key themes are the development of digital government, digital business, digital entrepreneurship, digital skills and values. Malaysia's main perspective

17 Thomas W. Hazlett, 'The 1927 Radio Act as Pre-emption of Common Law Property Rights', in: Review of Industrial Organization 56 (2020), 17-35.

18 Ibid., 19.

19 See, for example, Eva Potonska and Charlie Beckett (eds.), Public Service Broadcasting and Media Systems in Troubled European Democracies, Cham/CH 2019. 
on sovereign digital capacity building is the development of the national digital economy through AI and the Internet of Things while at the same time monitoring political content through an Anti-Fake News act, passed in 2019. Overall, national regulatory motives are technology-centered (e.g. addressing national access, standards), economy-centered, specifically with a focus on AI and Internet of Things, and social policy-centered (digital divide, health, literacy, privacy).

However, when viewed from a global perspective, these highly specific regulatory approaches are diverse and often conflicting. They are based primarily on digital economy motives whereas the transnational "horizontal" civic data spheres embedded today in all societies are rarely addressed. Questions have also to be raised why even the definition of social media platforms are today, at a time where data monopolies have gained such a dominant role for national communication, still understood in national terms and perceived as being embedded in national sovereign communicative space: In some countries social media platforms are seen as "content provider" (UK), to be held accountable for content dissemination, in others they are seen as "intermediaries" (such as in the US), involving almost no responsibility as they only serve as publisher of "third" party content. In developing countries, social media platforms are seen as a core backbone for the development of a digital economy which are - except for ad hoc shutdowns and in contexts of disseminating "fake news" - not included in regulation and which citizens use for all kinds of political debate. ${ }^{20}$

European nation-states have a tradition of safeguarding national public spheres. However, the core components of national sovereign communicative space, in European countries, (1) "public service" media and the role of journalism as a "fourth estate", (2) communication infrastructure to safeguard interaction and (3) jurisdiction to enable legal civic rights, are currently in flux and transitioning away from sovereign space towards spheres of influence of global data monopolies.

\section{(1) "De facto" public service by big tech to public service content embeddedness in proprietary platformization}

While public service is a core component of European media publics, the reality is that data monopolies are providing de facto "public service" for a digital society while at the same time, gathering "deep" microdata from citizens. Yet,

20 E.g. Tanja Bosch, Admire Mare and Meli Ncube, 'Facebook and Politics in Africa', in: Media, Culture and Society, 42 (2020), 349-364. 
a fundamental discussion of public service structures and remit - and, in fact, ecosystems - in digital times is missing. Platforms and search sites are used across European nation-states for political engagement and community building, for critical health information, political activism, and for crisis communication. More needs to be done to address public service in European dataified societies. Some debates emerged about a decade ago, suggesting to envision new types of public service by developing national social media and search engines that could be funded nationally, yet, made available internationally through new types of international partnerships. ${ }^{21}$ Others suggest to adopt a "network approach" as a regulatory mechanism of public service media in Europe which would allow to envision public service "transcending states".22

Data monopolies are situated almost in a parallel universe and are driven by unrestricted globalized growth through interlinked corporate monopolized "ecosystems" of data processing "stacks", such as Google, Google cloud, YouTube, Android, Chrome plus numerous related applications, such as google maps - without any public service obligations. Even the European Union does not engage in a debate about a European public service approach and, instead, falls back to the approach to regard digital monopolies as communication spaces under national sovereignty. While some scholars understand this process as "data colonialism", 23 others are concerned how traditional national news organizations are losing control. ${ }^{24}$ Others again feel that the term public service needs to be adjusted. ${ }^{25}$

Concerns are also raised regarding the transformation of public service national news organizations as digital intermediaries influence - through algorithms - public service media content "from inside". ${ }^{26}$ In such a scenario, "the implications for actors and organizations, occupying a less privileged position in the media environment - such as political campaigns [or] social movements"

21 Mark Andrejevic, 'Public Service Media Utilities: Rethinking Search Engines and Social Media as Public Goods', in: Media International Australia 146 (2013), 123-132.

22 Bissera Zankova, 'Public service media regulation in the new media environment: the role of networks for accelerating reforms', in: Michał Głowacki and Alicja Jaskiernia (eds.), Public Service Media Renewal: Adaptation to Digital Network Challenges, Frankfurt am Main 2018, 17-38, 32.

23 Nick Couldry and Ulises Mejas, 'Data Colonialism: Rethinking Big Data's Relation to the Contemporary Subject', in: Television \& New Media 20/4 (2018), 336-349; dies:.The Costs of Connection. How Data Is Colonizing Human Life and Appropriating It for Capitalism Stanford 2019.

24 E.g. Jose van Dijck, The Culture of Connectivity, A Critical History of Social Media, Oxford 2013. 25 For an overview see Głowacki and Jaskiernia (eds.), Public Service.

26 Jonathon Hutchinson, 'Intermediaries exercising Influence inside Public Service Media', in: ibid., 117-134. 
are likely to be profound. ${ }^{27}$ The transformation of societies and the disruption of democratic civic space through new processes of microtargeting, mobilization in election campaigns and the fracturing of the public is observed across developed and developing countries such as in Myanmar where the polarization of debates on Facebook contributes to the heightening of tensions between Buddhists and Muslims. While, for example in European countries, election campaign ads by national broadcasters are meticulously regulated, election campaigns on social media are on the periphery of policy approaches. The "Facebook Manifesto" released by Mark Zuckerberg in 2017 reveals the naive but concerning selfconfidence of a global tech monopoly to implement a global governing logic and to enable a "new process for citizens worldwide to participate in collective decision-making" and to explore "how community governance might work at scale". ${ }^{28}$ The fact that a protest in Tanzania in 2019 was initiated and coordinated daily by an expatriate living in New York City via social media reveals these scalable dimensions, in addition to the transnational scopes of transnational activism from "Occupy Wall Street" to "me too", to "Fridays for future" magnify these civic relations.

\section{(2) Data ecologies enabling civic interaction: from cloud to 5 G}

Decades ago, communication infrastructures were seen as national sovereign space. Telecommunication providers, for example, were traditionally state-owned before the WTO promoted the liberalization - the "open sky" policy - of the telecommunication sector in the early 1980s. European nation-states carefully drafted policy guidelines to ensure a balance between private and public interests in providing telecommunication as a backbone of societal interaction in the 1980s. While communication infrastructures, for example television cable systems at the time, were seen as a core sovereign space, in contrast, today, cloud computing as a core distribution and storage capacity for data communication was first very broadly regulated in the EU about a decade ago, providing very basic guidelines, mainly targeting the use of the cloud by industry. This is now updated by a recent draft of the European Cloud Initiative with the aim to build a "knowledge economy” in Europe for the public sector (i.e. government communication)

27 Rasmus Kleis Nielsen and Sarah Anne Ganter, 'Dealing with Digital Intermediaries: A Case Study of the Relation between Publishers and Platforms', in: New media \& Society 20/4 (2018), 1600-1617, here 1602.

28 Mark Zuckerberg, 'Building Global Community’ (2017), URL: https://www.facebook.com/ notes/mark-zuckerberg/building-global-community/10154544292806634/ (26-07-2020). 
and industry as a new European sovereign cloud space. However, the regulatory approach of this sovereign cloud space does not include the notion of cloud computing as "public service", the safeguarding of civil society interaction which constitutes an important dimension of European digital societies.

The traditions of regulating infrastructures on territorial sovereign space reach limits when addressing so called "OTT" - over-the-top-technologies. OTT's relate to content services, such as Netflix, to voice interaction, such as Skype and to messaging services, such as WhatsApp. These are services which were, decades ago, safeguarded by sovereign telecommunication infrastructures (see above). OTT cloud-based services operate beyond - i.e. “over the top" - of traditional distribution networks (satellite, cable, telecommunication) and beyond national territories. However, citizens across continents interact - and deliberate through these services and while, for example, Netflix is regulated regarding its content library (to include sufficient work of French origin, such as in France and Canada) but not regarding its practice of all sort of individual data point collection of its subscribers, like the choice of films, the stopping and continuing of streaming, geographical mobility of the user, for example, when travelling internationally and resuming the streaming of Netflix content in a hotel room. These are interactions no longer related to territorial place but, instead, cloud computing makes it difficult or even impossible to ascertain in real time "where specific data is located" 29 which means that the territorial principle of sovereignty is already outdated. The controversial discussion by governments of various European countries regarding the Chinese company Huawei to establish the crucial $5 \mathrm{G}$ infrastructure reveals how controversial governments in Europe perceive their sovereign space. Most arguments regarding a potential surveillance address, however, the safeguarding of industry. Debates rarely relate to the safeguarding of civic space which is also fully incorporated into $5 \mathrm{G}$ infrastructures.

\section{(3) The issue of jurisdiction - in fluid data spaces}

The third example relates to jurisdiction, a concept which so clearly emphasizes "territoriality" as the contextual legal regime. However, digital interaction operates in a globalized data world where it is no longer clear which domestic law applies to which aspect of the interaction. For example, relating to cloud computing, Svantesson argues that "whether intentionally or not, cloud computing typically creates connecting points to foreign jurisdictions in situations that

29 Dan Svantesson, Internet \& Jurisdiction - Global Status Report, Paris 2019, 48. 
may have previously been entirely domestic."30 Data are split over server geographies across countries and, as Svantesson notes, "even where the location of data may be ascertained, the mobility of data makes it possible to manipulate its location in order to hinder law enforcement." 31 The territoriality principle of sovereign jurisdiction requires a substantial revision in contexts of the globalized fluid data flows in which citizenship is embedded today. The European Unions' data policy, the General Data Protection Regulation (GDPR) also reaches its limits when aiming to target Google's layered - in Bratton's diction "stacked"32 - data structures. It also reaches its limits in terms of defining jurisdiction in sovereign territory as the GDPR relates to data stored on European servers. Although data of European citizens stored outside of the European Union is also subject to the GDPR, globalized micro data within a new world of artificial intelligence are difficult to track. Artificial Intelligence and blockchain data interaction are not territorially bounded. Furthermore, European citizens engage in civic debate with citizens outside of the EU which is a dimension not addressed at all. Big tech companies, from global data monopolies to smart television sets, gather not only civic data (which is addressed by numerous scholars) but threads of civic interaction. On smart home devices, for example, they have the potential to configure data profiles of European citizens' deliberation and reach deep into national sovereign space, leaving the issue of jurisdiction in these digital ecosystems unresolved.

These three examples reveal that motives, vocabulary and narratives of national sovereign dimensions of civic interaction that were so carefully defined in times of the national public sphere, exist side-by-side to globalized digital dimensions and cannot be extended or just adopted to address today's digital landscape. As van Dijck argues, the "ideal platform society does not exist, and it will be hard to recalibrate the Western-European Rhineland model (this is the Westphalian model, I.V.) to make it fit with the American ecosystem's infrastructural architecture that privileges commercial values over public ones."33 She notes that "public values and the common good" are at stakes "in the struggle over platformization around the globe."34

30 Ibid., 47.

31 Ibid., 104.

32 Bratton, The Stack.

33 Jose van Dijck, 'Governing Digital Societies: Private Platforms, Public Values', in: Computer Law \& Security Review 36 (2020) 1-4, 3.

34 Ibid, 4. 


\section{The data citizen, deliberating in globalized public spheres}

New paradigmatic approaches to sovereignty are required to address especially the safeguarding of civic interaction in transnational data spaces to ensure that citizens can interact without concerns of data exploitation in safe data ecologies with a clear understanding of digital governance and jurisdiction.

This can only be achieved through a holistic focus of democratic countries on the new formations of public spheres and new practices of deliberation within the new parameter of non-national, non-territorial publics. Public spheres are dense, multi-directional thematic discourses between place and space, where the individual citizen is no longer deliberating with fellow national citizens but with fellow citizens across all types of societies to critically assess national governance and reflecting new civic practices of achieving accountability and legitimacy measures. A first term to describe these practices is "digital citizenship" 35 to signify how citizens adopting technology fulfil their civic duties. More recent debates have a focus on the parallel civic worlds of online/offline; others suggest more democratic control of the overall public sphere in light of platformization. ${ }^{36}$ However, what is overlooked is the reality of new types, modes and formats of concrete practices of deliberation in an unfolding postterritorial data space. It is a postterritorial civic sphere, enhanced not only by social media platforms but by “deep” digitalization, the data links produced by citizens through interaction using individual digital interfaces, carefully selected interactive microsystems which include political interaction through apps, blogs, clips, and influencers across societies. ${ }^{37}$

Such a postterritorial civic data interaction can no longer be regulated through national "polity" with a focus on a national territorial geography as the exclusive national communicative space. As Kuner noted, in contexts of data privacy regulation, the focus on data geographies, hence an emphasis on national regulation, has reached its limits. ${ }^{38}$ Even the initiatives drafted by intergovernmental conventions (e.g. the OECD), binding under international law, however - and this is often overlooked - require "in most countries' conventions"

35 Karen Mossberger et al, Digital Citizenship. The Internet, Society and Participation, Cambridge 2008.

36 Sonja Vivienne, Anthony McCosker and Amelia Johns, 'Digital Citizenship as 'Fluid Interface;' Between Control, Contest and Culture', in: idem (eds.), Negotiating Digital Citizenship: Control, Contest and Culture, New York 2016, 1-18; van Dijck, Privat Platforms.

37 See further Ingrid Volkmer, The Global Public Sphere, Cambridge 2014.

38 Cf. Christopher Kuner, Transborder Data Flows and Data Privacy Law, Oxford 2013. 
to be "implemented in national law" and "may be measured against the standards of constitutional law." 39 In other words, dimensions of "polity" even in the aim to produce some international harmonized standards still relate back to national sovereign space. In consequence, governments negotiate directly with globalized big tech companies as if they were public actors - although they operate in national public policy debates without any civic legitimacy.

It has been argued that new policy motives of digital governance require foremost a definition of democratic public values to tackle the still ambiguous dimension of platform governance. This is needed, especially in a European perspective, as content platforms are "firmly cemented in an American based neoliberal set of principles". ${ }^{40}$ However, new policy motives are not only required for platform governance but a paradigm shift is needed away from a focus on often ad hoc approaches of digital and data governance towards a holistic focus on the reality of civic deliberation in globalized public spheres. Such a holistic conception is required to overcome the traditional notion of national communicative sovereign space - for example, reflected in the variety of national regulatory approaches to platform governance - and to overcome the often fractured attempts to regulate fluid global data spaces in a national or intergovernmental perspective. A new understanding of civic deliberation in postterritorial digital and data spheres enables, in a second step, to map out communicative sovereign space and to safeguard democratic civic deliberation which is no longer territorially bounded.

It is surprising that in democratic countries the perception of sovereign civic space is still somewhat associated to the Habermasian concept of national public spheres as a sphere for national citizens to deliberate (as reflected in national media regulation). National deliberation among the national citizens who are able to vote, produce in modern nation-states the rationale to assess accountability and legitimacy of democratic governance. The main linking component of the conceptualization of the public, of deliberation and legitimacy is the assumed territorial boundedness defining the "voting publics" of territorial polis and demos which are the core component of modern national normative legitimacy of polity over sovereign space. However, there are breaking points of this paradigmatic model and - strictly speaking - debates in political theory "mapped" the shift towards conceptions of transnational polities and governance structures beyond conventional modern state-centric model already some time ago. These assess the emerging post-territorialized space of civic interaction through a number of

39 Ibid., 162.

40 van Dijck, Private Platforms, 3. 
different paradigmatic lenses: through the lens of civil society, ${ }^{41}$ through the lens of a post-international world or in a German term, "Weltstaatlichkeit", as "world statehood" which understands the national or the territorial state itself as a sphere of globalization. ${ }^{42}$ Ferguson and Mansbach argue that, overall, "statecentric theories and models [. . .] account for only a small part of what happens in the world, and, at worst, are edifices built on sand" as the "interstate epoch is drawing to a close". ${ }^{43}$ In their view, the boundaries "that separate territorial states from one another" no longer "demarcate political spaces based on economic, social, or cultural interests" as each of these "has its own boundaries that in the face of localization and globalization are less and less compatible with the border of states." Consequently, the "conception of political space as largely synonymous with territory poses a barrier to theory-building in global politics."44

When addressing these new dimensions of deliberation in democratic countries, it is important to realize that the global spheres of public deliberation across digital data spaces not only include the traditional "Westphalian" state. The Habermasian understanding of deliberation among like-minded (national) citizens no longer applies as citizens of all types of societies engage in discourse "threads" via, for example, smart mobile devices that emerge as core communication platforms even in "failed" states. It is important to realize that citizens of all types of societies, from democratic "Western" to authoritarian and "failed" states, are - in regionally specific ways - drawn into such a globalized digital ecology. Citizens, for example in contexts of globalized risks, deliberate across societies in new dimensions of "reflective interdependence". ${ }^{45}$ It is a dimension of communicative globalization enabling transnational spatial relations where not only nations, "localities" but subjective interaction is entangled in globalized "deep" digital data formations. In other words, public communication rotates around what Luhmann might have described as "autopoietic", ${ }^{46}$ self-directed discourse "absorbing” public engagement across national borders into a differentiated "viral" public "system" - in today's jargon - "echo chambers" or "filter bubbles". This dynamic formation has

41 Mary Kaldor, Global Civil Society: An Answer to War. Basingstoke 2003.

42 See e.g. Rudolf Stichweh, ,Dimensionen des Weltstaats im System der Weltpolitik', in: Matthias Albert, idem, (eds.), Weltstaat und Weltstaatlichkeit, Beobachtungen globaler politischer Strukturbildung, Wiesbaden 2007, 25-36.

43 Yale H Ferguson and Richard W Mansbach, Remapping Global Politics. History's Revenge and Future Shock, Cambridge 2004, 4.

44 Ibid., 74.

45 See Volkmer, Public Sphere.

46 Niklas Luhmann, Soziale Systeme, Frankfurt/M. 1984. 
implications for civic identity relating to floating loyalties, detached from sovereign territorial boundedness. Civic identity, depending on deliberative practices might relate to the state but at other times to a social movement operating across territorial frontiers, at other times to a "family", we might add, a tribe, a generation, fellow-members of an occupation or profession. As early as 1996, the late Susan Strange has contended that we are faced with a "new absence of absolutes" and that "in a world of multiple, diffused authority" our "individual consciences are our only guide". ${ }^{47}$ An example is the Fridays for Future movement where civic identity is embedded in climate activism. In this sense, we could argue, referring to Ulrich Beck's notion of "self reflexivity" 48 that citizenship constitutes "reflexive citizenship" - embedded in reflexive transnational public discourse. This is a process which is enhanced by deliberation across globalized digital data spaces and has implications on the perception of legitimacy of polity - and national sovereign space.

These emerging dimensions of postterritorial digital interaction relate not only to new types of civic interaction but also transform already the democratic state which is also "dataified". From the datafication of the public sector, i.e. e-government, to digital elections (via Blockchain) to automated online communication with citizens, the structures of the democratic state are embedded in digital space. To understand the democratic state as a digital data space has to be addressed in a new dimension of sovereign communicative space. "As Saskia Sassen argues when addressing the deterritorialization of states, critical components of authority deployed in the making of the territorial state are shifting toward becoming strong capabilities for detaching that authority from its exclusive territory and onto multiple bordering systems. Insofar as many of these systems are operating inside the nation-state, they may be obscuring the fact that a significant shift has happened. It may take a while to become legible in its aggregate impact." 49 To tackle these processes, the "postterritoriality" of civic spheres requires new regulatory paradigms and - in consequence - new sets of policy motives and values in democratic and increasingly dataified societies. I use the term "postterritoriality" to underline the "non-placeness" and "fluid" modes of data flows of civic interaction which transcends across layers of globalized data geographies with constantly shifting centres and peripheries.

47 Susan Strange, The Retreat of the State: The Diffusion of Power in the World Economy, Cambridge 1996, 263-264.

48 Ulrich Beck, Cosmopolitan Vision, Cambridge 2006.

49 Saskia Sassen, Territory, Authority, Rights: From Medieval to Global Assemblages, Princeton 2006, 419-420. 


\section{Transnational regulatory regimes - towards a model of 'shared' sovereignty}

Based on the need to identify policy approaches to address civic interaction in globalized public discourse territories, it is useful to review the traditions of policy approaches regarding transnational communication and to assess how these reflected communicative sovereignty in transborder spaces.

Transborder regulation of national sovereign communicative spheres emerged already at the time of the telegraph, in the 19th Century. International telegraph transmission across continents was possible through underwater cables across the oceans and telegraph lines along railroads. In 1865, the International Telegraph Union (ITU) was established by twenty European states as an intergovernmental organization with the aim to draft the first international telegraph convention. This convention set first principles of transborder communication and defined the Morse code as the international alphabet, protected secrecy of correspondence and the right of everyone to use telegraphy. We could argue that these standards constituted first model to establish extraterritorial sovereignty of telegraph communication through an international regulatory body, yet, setting standards for national sovereign communication. In the following decades one of the ITU's main focus was the harmonization of the international radio frequency spectrum, again adopting standards that required alignment of national sovereign regulation. Even shortwave radio with its international reach, was seen as a national medium which, however, required technological standardization in a global context.

About a hundred years later, the regulation of satellites used for telecommunication - and, later, for television distribution - emerged as a new focus of the ITU's intergovernmental debates. Despite the fact that satellites were placed in non-national territory, in orbit, ITU's intergovernmental regulation identified a way to renationalize orbital slots. The ITU assigned specific orbital satellite slots to national telecom operators and this policy procedure established a second model of extraterritorial sovereignty of communication space. However, satellite television commenced in the late 1980s and enabled a new type of trans-border communication which made borders fuzzy as satellite "footprints", i.e. the area that is targeted by a satellite beam, cannot target specific countries. Based on the size, angle and power of the satellite beam, they can only target regions - sometimes only small geographical parts of countries. This posed an issue for satellite television regulation as the territorial principle so engrained in the understanding of communicative sovereignty had no longer relevance. In order to regulate satellite content, the EU passed the "Television without Borders" Directive in 1989 as a regulatory instrument which, on the one hand, maintained the free flow 
of content but, on the other, defined content jurisdiction by making the country where the satellite beam is uploaded (the national location of the relais station) accountable for content. This is called the "Country of Origin" principle which has guided the EU's transborder television policy for decades. Under the EU's “country of origin principle”, it is understood that broadcasters are only subject to the jurisdiction of the originating state. The "Country of Origin" principle can be seen as a turning point where international content dissemination, despite reaching citizens in the country directly via rooftop antennas and providing political information, are no longer seen as part of polity of sovereign communication territory of that country but the communicative connection enabled by the national position of the relais station determines the jurisdiction of the "country of origin”. Although, various United Nations' Agencies addressed globalized issues regarding building communication capacity for decades, a new initiative, launched in 2009, aimed to adopt a "holistic" perspective and to focus on capacity building of the global information society "as such". This initiative, called the World Summit on the Information Society (WSIS), drafted guiding principles for developing and developed regions to build communication capacity. The Declaration includes guidelines from technology development to close the "digital divide" to raising literacy, support of traditional media and enabling equal access to information. The WSIS declaration is one of the most coherent policy guidelines addressing the importance of public interaction across all types of societies. The WSIS framework sets the agenda for national digital capacity building and in this sense, reaches into sovereign space through intergovernmental approaches. Countries are required to develop their own national e-strategies to enable ICT capacity building which includes technological infrastructures but also digital literacy. However, the WSIS declarations are guidelines and constitute another type of extraterritorial sovereign approaches which, however, leave the actual execution of these guidelines to national governments.

Today the density of digital interaction has reached a point where a fundamental debate about the sovereignty of civic space is necessary. Given the rapid transformation of digital civic space and the transitioning of the digital citizen to a "data citizen", digital policy can no longer just target "ad hoc" issues but requires a reconception of the dimension of sovereignty to safeguard the new dimensions and the "logic" of civic interaction in a postterritorial sphere. It seems that the Westphalian concept of "polity" over sovereign territory is - in terms of digital policy - dissolving and tech companies assume polity power while the state is left to react and negotiate, for example with Mark Zuckerberg regarding the violent and populist content of Facebook, or regarding crypto currencies. Democratic states are entangled with a global civic tech universe in a way that requires a rethinking of traditional conceptions of sovereignty to protect civic 
space in democratic countries. Current policy debates suggest to assign ethical responsibility to data exporters and controllers who design algorithms and etablish the modality of AI sensors and accentutors. However, the term of "ethical" responsibility is rarely defined and remains ambiguous. I agree with Kuner who suggests that there is a "need to build bridges between different systems of transborder data flow regulation, which can be referred to as the concept of legal interoperability" as a term to refer "to measures taken to facilitate the interaction between regulatory systems across national borders."50

Such a "legal interoperability" cannot be achieved by applying the traditional extraterritorial approach implemented in the time of the telegraph and extended to other transborder communication where intergovernmental frameworks set the regulatory agenda which is - subsequently - adopted in very specific national terms, retaining national sovereignty over communication spheres and - ultimately, reaching controversial responses to address the unity of globalized big tech.

Given the postterritorial digital data space and the fact that citizens interact and deliberate in such a postterritorial public landscape, new approaches to communicative sovereignty are needed! As functioning communicative sovereignty the public sphere - is a crucial component of democratic societies, it might be time to suggest a model of "shared" communicative sovereignty among democratic countries. This would enable to counterbalance the otherwise unlimited power of tech monopolies on an international scale through a clearly defined, shared sovereign digital policy framework which homogenizes the digital policy approaches across democratic countries and avoid different national adoptions as we currently see (such as in terms of the definition of social media platforms). A model of shared sovereignty will be able to fully address the postterritorial reality of civic data interaction. The shared sovereignty model is also relevant for the transitioning of democratic societies and conceptions of citizenship into the AI sphere where territoriality is no longer an issue.

While the Westphalian model laid the foundation for a functioning international state order in the time of modernity, the model of shared sovereignty will establish and sustain the core component of democratic countries, a functioning and balanced public sphere, and to safeguard the future of democratic citizenship.

50 Kuner, Data Flows, 174. 